\title{
Morphological characterization of virus-like particles in coral reef sponges
}

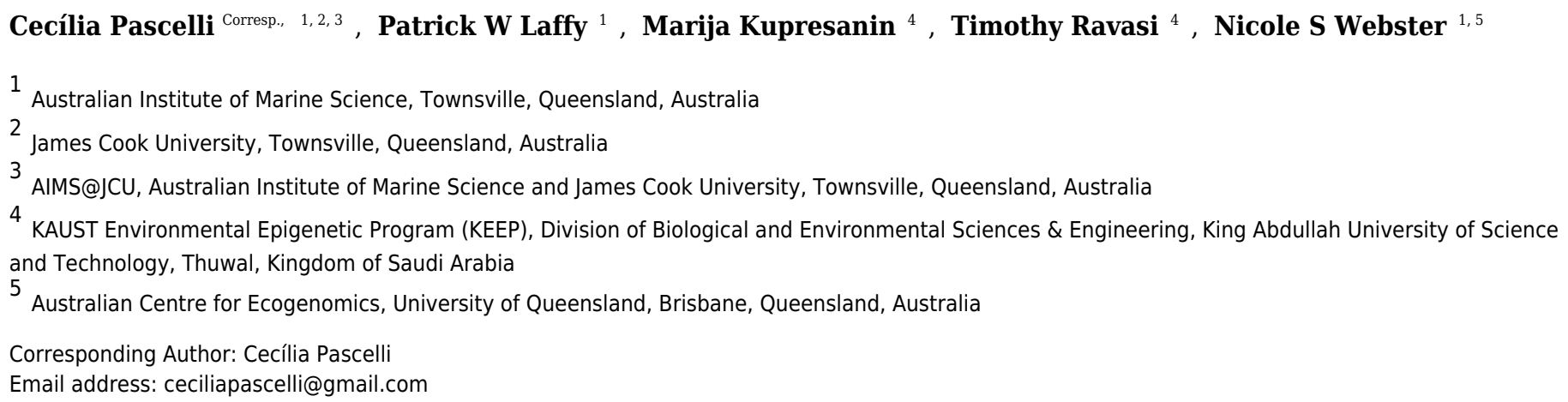

Marine sponges host complex microbial consortia that vary in their abundance, diversity and stability amongst host species. While our understanding of sponge-microbe interactions has dramatically increased over the past decade, little is known about how sponges and their microbial symbionts interact with viruses, the most abundant entities in the ocean. In this study, we employed three transmission electron microscopy (TEM) preparation methods to provide the first comprehensive morphological assessment of sponge-associated viruses. The combined approaches revealed 50 different morphologies of viral-like particles (VLPS) represented across the different sponge species. VLPs were visualized within sponge cells, within the sponge extracellular mesohyl matrix, on the sponge ectoderm and within sponge-associated microbes. Non-enveloped, non-tailed icosahedral VLPs were the most commonly observed morphotypes, although tailed bacteriophage, brick-shaped, geminate and filamentous VLPs were also detected. Visualization of sponge-associated viruses using TEM has confirmed that sponges harbor not only diverse communities of microorganisms but also diverse communities of viruses. 


\section{Morphological characterization of virus-like particles in coral 2 reef sponges}

3 Cecília Pascelli ${ }^{1,2,3}$, Patrick W. Laffy ${ }^{2}$, Marija Kupresanin ${ }^{4}$, Timothy Ravasi ${ }^{4}$ and Nicole S. Webster ${ }^{2,3,5}$

$4{ }^{1}$ James Cook University, Townsville, Queensland, Australia

$5 \quad 2$ Australian Institute of Marine Science, Townsville, Queensland, Australia

6 3 AIMS@JCU, Australian Institute of Marine Science and James Cook University, Townsville, Queensland,

7 Australia

$8 \quad{ }^{4}$ KAUST Environmental Epigenetic Program (KEEP), Division of Biological and Environmental Sciences \&

9 Engineering, King Abdullah University of Science and Technology. Thuwal 23955-6900. Kingdom of Saudi

10 Arabia

$11{ }^{5}$ Australian Centre for Ecogenomics, University of Queensland, Brisbane, Queensland, Australia

13 Corresponding Author:

14 Cecília Pascelli ${ }^{12}$

15 PMB No.3, Townsville MC, Townsville, Queensland, 4810, Australia

16 Email address: cecilia pascelli@gmail.com 


\section{Abstract}

21 Marine sponges host complex microbial consortia that vary in their abundance, diversity and

22 stability amongst host species. While our understanding of sponge-microbe interactions has

23 dramatically increased over the past decade, little is known about how sponges and their

24 microbial symbionts interact with viruses, the most abundant entities in the ocean. In this study,

25 we employed three transmission electron microscopy (TEM) preparation methods to provide the

26 first comprehensive morphological assessment of sponge-associated viruses. The combined

27 approaches revealed 50 different morphologies of viral-like particles (VLPs) represented across

28 the different sponge species. VLPs were visualized within sponge cells, within the sponge

29 extracellular mesohyl matrix, on the sponge ectoderm and within sponge-associated microbes.

30 Non-enveloped, non-tailed icosahedral VLPs were the most commonly observed morphotypes,

31 although tailed bacteriophage, brick-shaped, geminate and filamentous VLPs were also detected.

32 Visualization of sponge-associated viruses using TEM has confirmed that sponges harbor not

33 only diverse communities of microorganisms but also diverse communities of viruses. 


\section{Introduction}

Sponges are abundant and ecologically important members of marine benthic communities (Van Soest et al., 2012). Most sponges are suspension filter feeders (Thomassen \& Riisgård, 1995), with complex aquiferous systems capable of manipulating the seawater composition at both macro and micro scales (Vacelet \& Boury-Esnault, 1995; Patterson et al., 1997; de Goeij et al., 2013). A unidirectional (ostia-chamber-atrium-oscula) water flow driven by flagellated choanocyte cells is responsible for capturing and retaining small eukaryotes, prokaryotic cells and viral particles (Hadas et al., 2006). Sponge filtration of large quantities of seawater represents an important nutrient link between the pelagic and benthic environments (Pile \& Young, 2006), especially in oligotrophic ecosystems such as coral reefs (de Goeij et al., 2013).

Sponges form intimate partnerships with diverse microbial consortia, and these relationships range from mutualism to commensalism to parasitism (Webster \& Taylor, 2012; Thomas et al., 2016). The sponge microbiome is often highly conserved across individuals of the same sponge species but varies considerably across species (Thomas et al., 2016). It is because of these functionally important symbiotic partnerships that sponges are considered a typical example of a marine 'holobiont', an organism comprised of various 'bionts', living in symbiogenesis (Margulis \& Fester, 1991; Webster \& Thomas, 2016). However, while the symbiotic association between sponges and their bacterial / archaeal symbionts has been extensively studied (Schmitt et al., 2012; Thomas et al., 2016; Pita et al., 2018), the role of viruses in the sponge holobiont remain largely unknown, despite TEM images from the 1970s alluding to viral-infected sponge cells (Vacelet \& Gallissian, 1978), a demonstration of phage infection in a sponge-associated bacterium (Lohr, Chen \& Hill, 2005), and a few recent metagenomic studies providing insights into sponge virus diversity and function (Butina et al., 2015; Laffy et al., 2016, 2018).

Viruses are the most abundant biological agents in marine ecosystems, with about $10^{10}$ viruses per liter of surface seawater and $10^{10}$ per gram dry weight of marine sediment (Suttle, 2007; Danovaro et al., 2011). Importantly, viruses have the ability to regulate the prokaryotic and eukaryotic populations responsible for maintaining metabolic cycling in complex ecosystems such as coral reefs (Seymour et al., 2005; Thurber \& Correa, 2011; Mojica \& Brussaard, 2014). Viruses modulate microbial-driven processes through mortality, horizontal gene transfer and 
63

64

65

66

67

68

69

metabolic reprogramming by viral-encoded auxiliary metabolic genes (AMGs) (Bergh et al., 1989; Rohwer \& Thurber, 2009; Danovaro et al., 2011; Hurwitz et al., 2014; Breitbart et al., 2018). Recent years have seen an increased focus on the diversity and function of viruses associated with reef invertebrates including sea anemones (Wilson \& Chapman, 2001); starfish (Hewson et al., 2018); scleractinian corals and their associated microbial communities (Patten, Harrison \& Mitchell, 2008; Weynberg et al., 2014, 2017a; Laffy et al., 2018). However, while viruses have been described as essential components of coral reef ecosystems, capable of controlling microbial community dynamics, playing a role in coral bleaching / disease, and mediating reef biogeochemical cycling (Thurber et al., 2017), there is a paucity of research exploring viruses associated with ecologically important reef sponges.

Metagenomic analysis of purified viral fractions (metaviromics) recently provided the first insights into the composition and function of viruses inhabiting reef sponges (Laffy et al., 2016, 2018). Consistent with the pattern reported for sponge-associated microbial communities, the viral communities were found to be highly conserved within each sponge species, and displayed functional repertoires clearly distinct from viruses inhabiting the surrounding seawater (Laffy et al., 2018). Sequence analysis revealed that the metavirome assignments were dominated by viromes from the order Caudovirales but also contained representatives of the Mimiviridae, Phycodnaviridae, Circoviridae, Parvoviridae, Bidnaviridae and Microviridae. Unique viral adaptations to specific host microenvironments were also evident, with viral auxiliary genes being differentially represented across sponge species (Laffy et al., 2018).

While molecular approaches have substantially improved our understanding of viral-host interactions (Breitbart et al., 2002; Rosario \& Breitbart, 2011; Laffy et al., 2016), biases associated with DNA /RNA extraction methods (Wood-Charlson et al., 2015) and the limited genomic resources available for most environmental viruses (Roux et al., 2015) can still constrain our understanding of host-associated viral ecology. Transmission electron microscopy (TEM) is a powerful approach that has helped to reveal the morphology and distribution of viruslike particles (VLPs) in many marine hosts as well as deciphering patterns of host-viral interactions (Wilson \& Chapman, 2001; Patten, Harrison \& Mitchell, 2008; Brum, Schenck \& Sullivan, 2013; Pollock et al., 2014; Weynberg et al., 2017b). Here we use TEM to provide the 
92 first morphological characterization of viruses associated with 15 different coral reef sponge

93 species and confirm the spatial localization of these VLPs within the sponge holobiont.

94 Materials and Methods

95 Sponge collection and identification

96 Sampling was conducted on coral reefs of Orpheus Island, Great Barrier Reef, Australia

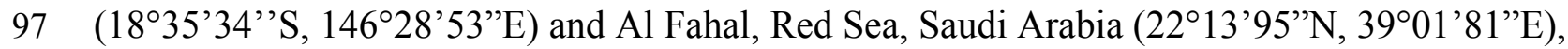
between December 2015 and February 2016. Sampling in Australia was conducted under the Great Barrier Reef Marine Park Authority permit G12/35236.1, and sampling in Saudi Arabia was authorized by the Saudi Arabian coastguard as the study did not involve endangered or protected species.

Triplicate specimens of 15 sponge species were collected by scuba diving between three and 15 meters depth. Two sponge species, Stylissa carteri and Carteriospongia foliascens were found at both locations, and sampling was performed in triplicate at both sites. Sponge specimens were photographed in situ before being individually placed within sterile Falcon ${ }^{\circledR}$ tubes and kept on ice until processing. All sampling materials were sterilized prior to and between each sampling. Morphological characterization of sponge species was performed as described in (Hooper \& Van Soest, 2002) and DNA barcoding was additionally performed using mitochondrial cytochrome oxidase I (COI) gene primers and internal transcriber spacer 2 (ITS2) region of nuclear ribosomal DNA as described in (Erwin \& Thacker, 2007; Andreakis, Luter \& Webster, 2012; Wörheide et al., 2012). Sponge species are described in Table 1 and can be seen in Figure S1

Three different sample preparation methods for TEM imaging of sponge-associated viruses were trialed: i) ultrathin sectioning of sponge tissue (Cheville \& Stasko, 2014); ii) purification of viral fractions via density gradient ultracentrifugation (Lawrence \& Steward, 2010; Weynberg et al., 2014) and iii) filtration of sponge mucus. All samples were examined using a Titan Cubed TEM and images were analyzed on the Cs-corrected Titan ${ }^{\mathrm{TM}}$ 80-300 platform at the Imaging Characterization Core Lab in KAUST. TEM search time was standardized to $1 \mathrm{hr} /$ sample. 
120 Histological sections were prepared from fresh sponge tissue based on standard procedures for 121 TEM (Cheville \& Stasko, 2014). Briefly, each fragment of approximately $1 \mathrm{~mm}^{3}$ was fixed in $1222.5 \%$ glutaraldehyde in $0.2 \mathrm{M}$ cacodylate buffer and kept at $4{ }^{\circ} \mathrm{C}$ for $2-24 \mathrm{~h}$. After fixation, samples were immersed in $1 \%$ osmium tetroxide in $100 \mathrm{mM}$ phosphate buffer for $1-2 \mathrm{~h}$, washed in distilled water and stained in the dark with $2 \%$ aqueous uranyl acetate for $2 \mathrm{~h}$ at $4{ }^{\circ} \mathrm{C}$. Stained tissue was dehydrated through a series of ethanol and propylene oxide then embedded in epoxy resin. Ectosome-choanosome oriented sections (about $65 \mathrm{~nm}$ thick) were prepared using a Leica EM UC7 ultramicrotome and placed on TEM copper grids.

\section{Viral purification via density gradient solution}

129

130

131

Viral purification was performed according to the fraction separation method by sedimentation in density gradients (Meselson, Stahl \& Vinograd, 1957), following the pre-processing approach established to isolate viruses from coral and sponge tissue (Weynberg et al., 2014; Laffy et al., 2018). In order to eliminate contaminants present in the aquiferous system, sponges were partially dried via repeated gentle squeezing alternated with rinses of filtered $(0.02 \mu \mathrm{m})$ seawater. Sponge tissue was then dissected into small pieces $\left(\sim 5 \mathrm{~mm}^{3}\right)$ and covered with $15 \mu \mathrm{L}$ of $0.02 \mu \mathrm{m}$ filter-sterilized (Anotop, Whatman) SM buffer (100 mM NaCl, 8 mM MgSO4, $50 \mathrm{mM}$ Tris pH 7.5), then homogenized with a Craig's HS30E homogenizer (Witeg, Germany) for 5 to 10 minutes (min). Tissue homogenate was filtered through a Falcon ${ }^{\circledR} 100 \mu \mathrm{m}$ Cell Strainer (Corning, USA), then centrifuged at $500 \mathrm{~g}$ for $15 \mathrm{~min}$ at $4^{\circ} \mathrm{C}$ to pellet the majority of cell debris. The supernatant was used to purify the VLP via centrifugation in Cesium Chloride solution, with density varying from $1.2 \mathrm{~g} / \mathrm{mL}$ to $1.6 \mathrm{~g} / \mathrm{mL}$ (Weynberg et al., 2014). After ultracentrifugation, sponge VLPs were collected from the fractions with densities between $1.2 \mathrm{~g} / \mathrm{mL}$ and $1.5 \mathrm{~g} / \mathrm{mL}$. In order to exchange the buffer and remove $\mathrm{CsCl}$ salts, samples were loaded onto $30 \mathrm{KDa}$ Amicon centrifugal spin columns (Millipore, EUA) and centrifuged at $4000 \mathrm{~g}$ for $30 \mathrm{~min}$ at $4{ }^{\circ} \mathrm{C}$. This process was repeated four-six times per sample. Filter- sterilized SM Buffer was added to the concentrate and all flow-through was discarded. The concentrate was fixed in $0.5 \%$ glutaraldehyde and kept at $4^{\circ} \mathrm{C}$ until TEM analysis. TEM preparation involved applying a droplet of sample onto a TEM Copper grid, rinsing with sterile water, staining with $1 \%$ uranyl 
148 acetate for one min, washing with sterile water, followed by removal of excess liquid from the

149 grid by touching filter paper to the edge.

150

151

152

153

154

\section{Viral purification via filtration of sponge mucus}

To describe the VLPs associated with sponge mucus and the external ectoderm, the sponge surface was carefully scraped with a sterile scalpel blade followed by rinsing three times with filtered $(0.02 \mu \mathrm{m})$ seawater. This TEM preparation method was based on a viral purification method described for marine hydras (Grasis et al., 2014). Extracted mucus was added to filtered $(0.02 \mu \mathrm{m})$ Milli-Q ${ }^{\circledR}$ water (1:4) and centrifuged at 4000g for 10 minutes. Mucus supernatant was filtered through $0.45 \mu \mathrm{m}$ filters (EMD Millipore, EUA) and fixed in $1.5 \%$ glutaraldehyde. TEM imaging of mucus preparations was performed as described above for $\mathrm{CsCl}$ purified samples.

\section{Results}

\section{Sponge associated viruses}

TEM analysis revealed that viral particles are diverse constituents of the sponge holobiont. Fifty VLP morphotypes (Fig. 1-5; Table S1; Morphotypes: M-I - M-L) were found in association with eight coral reef sponge species from the Great Barrier Reef: Carteriospongia foliascens, Stylissa carteri, Xestospongia sp., Pipestela candelabra, Lamellodysidea herbacea, Cymbastella marshae, Echinochalina isaaci and Cinachyrella schulzei; and seven sponge species from the Red Sea: Carteriospongia foliascens, Stylissa carteri, Xestospongia testudinaria, Hyrtios erectus, Mycale sp., Amphimedon ochracea and Crella cyathophora. VLPs were observed within sponge cells, in the extracellular mesohyl matrix, in the mucus/surface biofilm and within sponge-associated microbes. A diverse range of viral morphologies were observed, including hexagonal (tailed and non-tailed), spherical, filamentous, brick-shaped, beaded and geminate VLPs. While we detected numerous viral morphotypes, most were rare and often obscured by vesicles, cell debris and particulate organic matter.

Most sponge-associated VLP morphotypes possessed an icosahedral/polyhedral symmetry $(\sim 75 \%)$, ranging from $60-205 \mathrm{~nm}$ in diameter (Fig. $1 ; 2 ; 3 ; 4 \mathrm{~A})$. Tails were evident on some VLPs, confirming the presence of viruses from the bacteriophage order Caudovirales. Tailed VLPs were tentatively assigned to the three Caudovirales families based on their capsid 
176 symmetry and tail size/shape. VLPs characteristic of the Podoviridae presented a short tail

177 attached to a non-enveloped icosahedral capsid and these VLPs were observed in the sponges $C$.

178 foliascens (Fig. 1A), Xestospongia sp. (Fig. 1B), E. isaaci (Fig. 1C) and S. carteri (Fig. 1D).

179 VLPs characteristic of the Siphoviridae presented an icosahedral head with a long non-

180 contractile tail and these VLPs were detected in the surface biofilm of C. schulzei (Fig. 1E).

181 VLPs characteristic of the Myoviridae presented an icosahedral head and a long contractile

182 tail and these VLPs were observed in the sponges E. isaaci (Fig. 1F, G), S. carteri (Fig. 1H) and

183 A. ochracea (Fig. 1I).

184 Non-tailed icosahedral/polyhedral VLPs were observed using all three TEM preparation

185 methods. Particle sizes ranged from 60 to $205 \mathrm{~nm}$ in diameter and some presented an electron

186 dense core inside the viral capsid (35-124 $\mathrm{nm}$ in diameter). The majority of VLPs did not show

187 an envelope outside the capsid, however an envelope was observed in association with a small

188 proportion of VLPs (Fig. 2E; 3K-L; 5H). A typical example of an enveloped VLP was observed

189 in Hyrtios erectus where a group of four virions were observed within a vacuole in the mesohyl

190 matrix (Fig. 3L) and another free virion was captured merging its envelope into the cell

191 membrane of the host (Fig. 3K).

192 In addition to the polyhedral VLPs, eight morphotypes of filamentous virus-like particles

193 (FVLPs) were observed in the sponge mucus, mesohyl matrix, within sponge cells and

194 associated with sponge-associated microorganisms (Fig. 4C-L; 5A). These morphotypes varied

195 greatly in size (100-1300 nm length, 12-60 nm width) and shape. Rod-shaped FVLPs were

196 detected in the $\mathrm{CsCl}$ purified viral fraction of Xestospongia sp. (Fig. 4C, D) and the mucus of $S$.

197 carteri (Fig. 4I). Although similar, the $S$ carteri bacilliform VLPs were longer than those

198 observed in Xestospongia sp. (230 nm long, $19 \mathrm{~nm}$ wide in S, carteri; 120-130 nm long, $18 \mathrm{~nm}$

199 wide in Xestospongia sp.). In C. foliascens, a FVLP was frequently observed attached to

200 cyanobacteria and within the sponge mesohyl, (Fig. 4F-G). This FVLP resembled viruses of the

201 family Inoviridae due to their shortened body (100-130 nm length, 50-60 nm width) and

202 electron-translucent core with outer membrane structures consistent with a glycoprotein coat

203 surrounding the entire membrane (Ploss \& Kuhn, 2010). In X. testudinaria, a FVLP morphotype

204 was observed within cells and dispersed throughout the mesohyl (Fig. 4J-L). This thin, elongated

205 FVLP (340-1300 nm long and 15-30 nm wide) was observed at high abundance inside some 
206

207

208

209

210

211

212

213

214

215

216

217

218

219

220

221

222

223

224

225

226

227

228

229

230

231

232

233

choanocyte cells and lysed cells releasing virions were also evident (Fig. 4J-L). Another distinct FVLP morphotype was evident in the sponge mucus of C. cyathophora (Fig. 5A). It presented a tube-like shape indicating helical symmetry and size ranging from 150-154 nm in length and 22$25 \mathrm{~nm}$ in width.

Geminate VLPs were observed in C. cyathophora mesohyl matrix (Fig. 5B), in L. herbacea mucus (Fig. 5C), and found infecting filamentous cyanobacteria associated with the sponge $A$. ochracea (Fig. 5D-G). The cyanobacteria associated VLPs shared morphological traits with viruses from the family Geminiviridae (Li, Ou \& Zhang, 2013) and were typically twinned (81$95 \mathrm{~nm}$ long, 37-48 nm wide), comprising two quasi-isometric particles (34-45 nm length). The VLPs were spread across the cytoplasm, thylakoid lumen, and vacuoles of the cyanobacterial cells and were often at high abundance surrounding the stellar bodies (Fig. 5F).

A brick-shaped VLP morphotype, closely resembling viruses from the Poxviridae, was observed in sections of Crella cyathophora (Fig. $5 \mathrm{H})$. This morphotype had a complex structure comprising a biconcave core encased within a double layer membrane with two lateral bodies surrounded by an ovoid envelope (Buller \& Palumbo, 1991). Three representatives of this morphotype were observed within the sponge mesohyl matrix, and a single non-enveloped VLP was also observed in close proximity to a lysed sponge cell.

A beaded VLP was observed in sections of the sponges $C$. foliascens (Fig. 5I) and H. erectus (Fig. 5J-L). In C. foliascens, the branched VLP was $340 \mathrm{~nm}$ long, and was comprised of six beads, each measuring 30-35 $\mathrm{nm}$ in diameter. In H. erectus, the VLPs varied from 80 to $350 \mathrm{~nm}$ in length and were composed of 2-8 aligned beads with diameters ranging from $36-42 \mathrm{~nm}$. This morphotype was observed as isolated VLPs, attached to extracellular vacuole membranes in the sponge mesohyl, and within intracellular vacuoles of archaeocyte cells.

\section{Discussion}

Sponges are complex holobionts that host a diverse array of bacteria, archaea, and eukaryotic microorganisms (Fan et al., 2012, 2013; Webster \& Thomas, 2016). Whilst previous publications have alluded to the potential importance of viruses in sponges (Claverie et al., 2009; Webster \& Taylor, 2012; Laffy et al., 2016, 2018), including in sponge disease (Luter, Whalan \& Webster, 
234 2010), this study provides the first visual evidence that viruses are diverse components of the 235 sponge holobiont. The broad range of VLP morphologies visualised across the 15 different 236 sponge species is consistent with recent molecular data showing sponges harbour diverse 237 communities of viruses.

238 The frequent detection of multiple viral morphotypes within a single sponge species most likely 239 reflects the large number of potential hosts within the sponge holobiont (sponge cells, bacteria, 240 archaea, microeukaryotes). However, it is also possible that multiple viruses infect the same 241 host, as has been observed in some bacterioplankton (Holmfeldt et al., 2007) and corals (Thurber $242 \&$ Correa, 2011). Similarly, the same viral morphotype may infect multiple hosts within the 243 holobiont, as recently highlighted from phage-bacteria network analyses (Flores et al., 2011; 244 Flores, Valverde \& Weitz, 2013). This is particularly relevant considering the role of viruses in 245 lateral gene transfer between hosts and their subsequent effects on host metabolism (Breitbart et 246 al., 2018). Observed viral morphotypes may also not be native to the holobiont, as some may 247 have been extracted from the virioplankton by the sponge's aquiferous system. Although the 248 isolation methods employed in this study unveiled a wide range of VLP morphotypes, no 249 quantitative assessments were undertaken. To further our understanding of viral dynamics within the sponge holobiont, quantitative studies that count the number of VLPs per known tissue area, perform quantitative transmission electron microscopy (qTEM) (Brum, Schenck \& Sullivan, 2013), flow cytometry (Brussaard, 2004; Pollock et al., 2014) or fluorescent staining (Leruste, Bouvier \& Bettarel, 2012; Pollard, 2012) should also be performed.

Morphology is an important feature for viral classification according the International Committee on Taxonomy of Viruses (ICTV). However, there are also some limitations associated with using TEM to identify viruses. For instance, many viral groups lack morphological structures that characterize them as typical viral particles by TEM. Also, as many viruses are small and simple they can be mistaken for non-viral particles such as cellular vesicles or organelles. Although the assignment of viral-like particles in this study was made by comparison to morphologically characterised viruses, the possibility remains that some VLPs may not represent true viruses. 
262 In this study, TEM analysis revealed a prevalence of polyhedral VLPs with characteristic

263 bacteriophage morphology, consistent with what has been described for other marine

264 invertebrates (Wilson et al., 2005; Davy et al., 2006; Davy \& Patten, 2007; Patten, Harrison \&

265 Mitchell, 2008). The presence of Caudovirales-like morphotypes highlights the potential for

266 these VLPs to target sponge symbionts and ultimately control microbial population dynamics

267 within the sponge holobiont. Amongst them, a Siphoviridae VLP detected in the surface biofilm

268 of $C$. schulzei presented similar morphology, although slightly smaller, to the previously

269 described sponge-associated Phage ФJL001 (Lohr, Chen \& Hill, 2005).

270 Surprisingly, relatively few tailed bacteriophage were detected within the reef sponges,

271 despite the dominance of Caudovirales within the assigned sponge viromes (Laffy et al., 2018).

272 Although the dominance of tailed viruses in aquatic ecosystems is well characterised (Mizuno et

273 al., 2013; Weynberg et al., 2017; Thurber et al., 2017; Laffy et al., 2018), results from

274 morphological analysis of uncultivated viruses vary with respect to the relative dominance of

275 tailed (Cochlan et al., 1993; Colombet et al., 2006; Dutova \& Drucker, 2013) versus non-tailed

276 (Bergh et al., 1989; Wommack et al., 1992; Auguet, Montanié \& Lebaron, 2006; Brum, Schenck

277 \& Sullivan, 2013) VLPs. The reduced number of tailed VLPs in morphological descriptions has

278 been attributed to the destruction of the delicate VLP structures during centrifugation and TEM

279 sample preparation (Cochlan et al., 1993; Proctor, 1997). However, Brum et al. (2013) have

280 shown that sample preservation and preparation do not alter the morphological characteristics of

281 seawater derived VLPs (Brum, Schenck \& Sullivan, 2013) and non-tailed VLP have therefore

282 been proposed as the dominant viral group in aquatic ecosystems (Brum, Schenck \& Sullivan,

283 2013; Kauffman et al., 2018). Nevertheless, in this study, tailed VLPs were almost exclusively

284 detected in samples purified via filtration of mucus or scraping of the external biofilm, the least

285 disruptive of the three TEM preparation methods. This suggests that tailed VLPs are either more

286 abundant on the external surface of the sponge or that TEM preparation method could bias the

287 detection of tailed VLPs in sponges by mechanically damaging or distorting viral structures.

288 Filamentous viral-like particles (FVLP) were detected in both prokaryotic and eukaryotic cells

289 within the sponge holobiont. In C. foliascens, multiple individual Inoviridae-like VLPs were

290 observed attached to the surface of cyanobacteria, although no virions were observed inside the

291 cells. The absence of intracellular FVLPs combined with the absence of a dense core in these 
292 morphotypes provides further support for their classification as putative Inoviridae, as the 293 replication mechanism of this viral family often relies on the virus injecting its DNA into the 294 host cell and getting extruded without inducing cell lysis (Bayer \& Bayer, 1986; Russel, 1991; 295 Ploss \& Kuhn, 2010). A previous study demonstrated that temperate viruses are relatively less 296 abundant within host cells at high density (McDaniel et al., 2002).

297 FVLPs with helicoidal symmetry resembling Spiraviridae were detected in the sponge $C$.

298 cyathophora, with this viral family known to infect Archaea (Mochizuki et al., 2012). FVLPs

299 were also observed infecting eukaryotic cells in X. testudinaria. Abundant elongated and flexible

300 FVLPs were also detected in the archaeocytes and extracellular mesohyl matrix of $X$.

301

302

303

304

305

306

307

308

309

310

311

312

313

314

315

316

317

318

319

320

321

testudinaria (Fig. 4J-L). The point of host cell lysis was captured with a recently burst cell releasing virions into the extracellular matrix (Fig. 4J-K), characteristic of typical lytic viral infection (Dyson et al., 2015). Morphologically similar filamentous VLPs have been detected in coral mucus and associated Symbiodinium and were characterised as a coral-infecting RNA virus (Davy et al., 2006; Weynberg et al., 2017b). There is a general lack of studies investigating filamentous viruses in marine invertebrates, although metaviromic sequencing recently detected sequences assigned as filamentous viruses of the family Inoviridae in Great Barrier Reef sponges (Laffy et al., 2018).

VLPs morphologically consistent with viruses from the family Geminiviridae were observed in association with cyanobacteria in the sponge A. ochracea. Geminiviridae-like viruses have been isolated from infected freshwater cyanobacteria (Li, Ou \& Zhang, 2013), and, with the exception of being slightly smaller (79 $\pm 5 \mathrm{~nm}$ in length, $28 \pm 3 \mathrm{~nm}$ in diameter), the geminate VLPs from A. ochracea were morphologically similar. Most infected cyanobacterial cells had dense populations of these VLPs (Fig. 5D-G), although no lysed cells or free geminate VLPs were observed in the sponge mesohyl. However, several extracellular vesicles containing VLPs were observed, indicating that VLPs could use cell extrusion as part of their reproductive cycle. A geminate VLP has previously been isolated from mucus secreted by scleractinian corals (Davy \& Patten, 2007), however the morphology differs from the A. ochracea VLP, since it is notably bigger (about $145 \mathrm{~nm}$ in length, $82 \mathrm{~nm}$ width), with each isomer being wider than they are long, contrasting with the isomer dimensions in the A. ochracea VLP. Beaded VLPs were also detected in sponges and their non-isomeric particles comprising a flexible filament strongly 
322 resembled the beaded VLPs previously reported from scleractinian corals (Davy \& Patten, 2007;

323 Lawrence et al., 2015).

324 Brick-shaped VLPs closely resembling viral morphotypes from the family Poxviridae were 325 observed within the mesohyl of Crella cyathophora, a (Fig. 5H). Typical of enveloped viruses, 326 poxviruses use their envelopes to connect and fuse with their host membrane so that the viral 327 capsid is injected directly into the host cell (Moss, 2012). Poxviruses are notable pathogens, 328 infecting a wide host range among vertebrate and invertebrate taxa (Bracht et al., 2006; Grasis et 329 al., 2014; Haller et al., 2014). In the marine environment, they have been reported associated 330 with cetaceans and pinnipeds (Bracht et al., 2006) and more recently, analysis of sponge 331 metaviromes detected sequences affiliated to Poxviridae in Amphimedon queenslandica and 332 Ianthella basta (Laffy et al., 2018).

\section{Conclusion}

334 In this study we validated the efficacy of three different methods for TEM imaging of spongeassociated viruses: i) ultrathin sections of sponge tissue, ii) purification via density gradient ultracentrifugation and iii) ectoderm scraping and filtration of sponge mucus. While density gradient purification facilitated concentration and recovery of VLPs from different areas of the sponge holobiont, it also co-concentrated cellular debris, potentially masking many VLPs. Tissue sectioning enabled direct visualisation of spatial localisation and host-viral interactions but was labour intensive and some VLP structures were distorted during sectioning. Ectoderm scraping and collection of sponge mucus was most effective at preserving delicate viral structures and minimizing the amount of cellular debris, however, it was restricted to recovering VLPs associated with the sponge mucus or ectoderm.

This first morphological characterisation of sponge-associated viruses revealed a wide diversity of VLPs infecting both the sponge cells and symbiont compartments of the holobiont. By confirming that viruses are a significant component of the sponge holobiont, this work paves the way for future metaviromic and cell culturing analyses that can characterise the taxonomy and

348 function of the sponge viral community.

\section{Acknowledgements}


350 The authors wish to acknowledge Dr. Karen Weynberg for support with the microscopy samples

351

352

353

354

355

356

357

358

359

360

361

362

363

364

365

366

367

368

369

370

371

372

373

374

375

376

377

378

379

380

381

382

383

384

385

386

preparation and Dr. Rachid Sougrat and Dr. Ptissam Bergam for support with the operation of the TEM.

\section{References}

Andreakis N., Luter HM., Webster NS. 2012. Cryptic speciation and phylogeographic relationships in the elephant ear sponge Ianthella basta (Porifera, Ianthellidae) from northern Australia. Zoological Journal of the Linnean Society 166:225-235. DOI: 10.1111/j.1096-3642.2012.00848.x.

Bayer ME., Bayer MH. 1986. Effects of bacteriophage fd infection on Escherichia coli HB11 envelope: a morphological and biochemical study. Journal of virology 57:258-66.

Bergh Ø., BØrsheim KY., Bratbak G., Heldal M. 1989. High abundance of viruses found in aquatic environments. Nature 340:467-468. DOI: 10.1038/340467a0.

Bracht AJ., Brudek RL., Ewing RY., Manire CA., Burek KA., Rosa C., Beckmen KB., Maruniak JE., Romero CH. 2006. Genetic identification of novel poxviruses of cetaceans and pinnipeds. Archives of Virology 151:423-438. DOI: 10.1007/s00705-005-0679-6.

Breitbart M., Bonnain C., Malki K., Sawaya NA. 2018. Phage puppet masters of the marine microbial realm. Nature Microbiology. DOI: 10.1038/s41564-018-0166-y.

Breitbart M., Salamon P., Andresen B., Mahaffy JM., Segall AM., Mead D., Azam F., Rohwer F. 2002. Genomic analysis of uncultured marine viral communities. Proceedings of the National Academy of Sciences of the United States of America 99:14250-14255. DOI: 10.1073/pnas.202488399.

Brum JR., Schenck RO., Sullivan MB. 2013. Global morphological analysis of marine viruses shows minimal regional variation and dominance of non-tailed viruses. The ISME Journal 7:1738-1751. DOI: 10.1038/ismej.2013.67.

Butina TV., Potapov SA., Belykh OI., Belikov SI. 2015. Genetic diversity of cyanophages of the myoviridae family as a constituent of the associated community of the Baikal sponge Lubomirskia baicalensis. Russian Journal of Genetics 51:313-317. DOI: 10.1134/S1022795415030011.

Cheville NF., Stasko J. 2014. Techniques in Electron Microscopy of Animal Tissue. Veterinary Pathology 51:28-41. DOI: 10.1177/0300985813505114.

Claverie JM., Grzela R., Lartigue A., Bernadac A., Nitsche S., Vacelet J., Ogata H., Abergel C. 2009. Mimivirus and Mimiviridae: Giant viruses with an increasing number of potential hosts, including corals and sponges. Journal of Invertebrate Pathology 101:172-180. DOI: 10.1016/j.jip.2009.03.011.

Danovaro R., Corinaldesi C., Dell'Anno A., Fuhrman JA., Middelburg JJ., Noble RT., Suttle CA. 2011. Marine viruses and global climate change. FEMS Microbiology Reviews 35:9931034. DOI: $10.1111 / \mathrm{j} .1574-6976.2010 .00258 . x$. 
387

Davy S., Burchett S., Dale A., Davies P., Davy J., Muncke C., Hoegh-Guldberg O., Wilson W. 2006. Viruses: agents of coral disease? Diseases of Aquatic Organisms 69:101-110. DOI: $10.3354 /$ dao069101.

Davy JE., Patten NL. 2007. Morphological diversity of virus-like particles within the surface microlayer of scleractinian corals. Aquatic Microbial Ecology 47:37-44. DOI: 10.3354/ame047037.

de Goeij JM., van Oevelen D., Vermeij MJA., Osinga R., Middelburg JJ., de Goeij AFPM., Admiraal W. 2013. Surviving in a Marine Desert: The Sponge Loop Retains Resources Within Coral Reefs. Science 342:108-110. DOI: 10.1126/science.1241981.

Dyson ZA., Tucci J., Seviour RJ., Petrovski S. 2015. Lysis to Kill: Evaluation of the Lytic Abilities, and Genomics of Nine Bacteriophages Infective for Gordonia spp. and Their Potential Use in Activated Sludge Foam Biocontrol. PLOS ONE 10:e134512. DOI: 10.1371/journal.pone.0134512.

Erwin PM., Thacker RW. 2007. Phylogenetic analyses of marine sponges within the order Verongida: A comparison of morphological and molecular data. Invertebrate Biology 126:220-234. DOI: 10.1111/j.1744-7410.2007.00092.x.

Fan L., Liu M., Simister R., Webster NS., Thomas T. 2013. Marine microbial symbiosis heats up: the phylogenetic and functional response of a sponge holobiont to thermal stress. The ISME journal 7:991-1002. DOI: 10.1038/ismej.2012.165.

Fan L., Reynolds D., Liu M., Stark M., Kjelleberg S., Webster NS., Thomas T. 2012. PNAS Plus: Functional equivalence and evolutionary convergence in complex communities of microbial sponge symbionts. Proceedings of the National Academy of Sciences 109:E1878E1887. DOI: 10.1073/pnas.1203287109.

Grasis JA., Lachnit T., Anton-Erxleben F., Lim YW., Schmieder R., Fraune S., Franzenburg S., Insua S., Machado G., Haynes M., Little M., Kimble R., Rosenstiel P., Rohwer FL., Bosch TCG. 2014. Species-specific viromes in the ancestral holobiont hydra. PLoS ONE 9. DOI: 10.1371/journal.pone.0109952.

Hadas E., Marie D., Shpigel M., Ilan M. 2006. Virus predation by sponges is a new nutrient-flow pathway in coral reef food webs. Limnology and Oceanography 51:1548-1550. DOI: 10.4319/1o.2006.51.3.1548.

Haller SL., Peng C., McFadden G., Rothenburg S. 2014. Poxviruses and the evolution of host range and virulence. Infection, Genetics and Evolution 21:15-40. DOI: 10.1016/j.meegid.2013.10.014.

Hewson I., Bistolas KSI., Quijano Cardé EM., Button JB., Foster PJ., Flanzenbaum JM., Kocian J., Lewis CK. 2018. Investigating the Complex Association Between Viral Ecology, Environment, and Northeast Pacific Sea Star Wasting. Frontiers in Marine Science 5. DOI: 10.3389/fmars.2018.00077.

Holmfeldt K., Middelboe M., Nybroe O., Riemann L. 2007. Large variabilities in host strain susceptibility and phage host range govern interactions between lytic marine phages and their Flavobacterium hosts. Applied and Environmental Microbiology 73:6730-6739. DOI: 
Hooper JNA., Van Soest RWM. 2002. Systema Porifera. A Guide to the Classification of Sponges. Invertebrate Systematics 18:233-234. DOI: http://dx.doi.org/10.1007/978-1-46150747-5 1.

Hurwitz BL., Westveld AH., Brum JR., Sullivan MB. 2014. Modeling ecological drivers in marine viral communities using comparative metagenomics and network analyses. Proceedings of the National Academy of Sciences 111:10714-10719. DOI: 10.1073/pnas.1319778111.

Laffy PW., Wood-Charlson EM., Turaev D., Jutz S., Pascelli C., Botté ES., Bell SC., Peirce TE., Weynberg KD., van Oppen MJH., Rattei T., Webster NS. 2018. Reef invertebrate viromics: diversity, host specificity and functional capacity. Environmental microbiology. DOI: 10.1111/1462-2920.14110.

Laffy PW., Wood-charlson EM., Turaev D., Weynberg KD., Botté ES., Oppen MJH Van., Webster NS., Rattei T. 2016. HoloVir: A Workflow for Investigating the Diversity and Function of Viruses in Invertebrate Holobionts. 7:1-15. DOI: 10.3389/fmicb.2016.00822.

Lawrence JE., Steward GF. 2010. Purification of viruses by centrifugation. In: Manual of Aquatic Viral Ecology. 166-181. DOI: 10.4319/mave.2010.978-0-9845591-0-7.166.

Li S., Ou T., Zhang Q. 2013. Two virus-like particles that cause lytic infections in freshwater cyanobacteria. Virologica Sinica 28:303-305. DOI: 10.1007/s12250-013-3339-0.

Margulis L., Fester R. 1991. Symbiosis as a source of evolutionary innovation: Speciation and morphogenesis. Cambridge (Mass.): MIT press.

McDaniel L., Houchin LA., Williamson SJ., Paul JH. 2002. Lysogeny in marine Synechococcus. Nature 415:496-496. DOI: 10.1038/415496a.

Mochizuki T., Krupovic M., Pehau-Arnaudet G., Sako Y., Forterre P., Prangishvili D. 2012. Archaeal virus with exceptional virion architecture and the largest single-stranded DNA genome. Proceedings of the National Academy of Sciences 109:13386-13391. DOI: 10.1073/pnas.1203668109.

Mojica KDA., Brussaard CPD. 2014. Factors affecting virus dynamics and microbial host-virus interactions in marine environments. FEMS Microbiology Ecology 89:495-515. DOI: 10.1111/1574-6941.12343.

Moss B. 2012. Poxvirus Cell Entry: How Many Proteins Does it Take? Viruses 4:688-707. DOI: $10.3390 / \mathrm{v} 4050688$.

Patten NL., Harrison PL., Mitchell JG. 2008. Prevalence of virus-like particles within a staghorn scleractinian coral (Acropora muricata) from the Great Barrier Reef. Coral Reefs 27:569580. DOI: 10.1007/s00338-008-0356-9.

Patterson MR., Chernykh VI., Fialkov VA., Savarese M. 1997. Trophic effects of sponge feeding within Lake Baikal's littoral zone. 1. Insitu pumping rates. Limnology and Oceanography 42:171-178. DOI: 10.4319/1o.1997.42.1.0171. 
465

Pile AJ., Young CM. 2006. The natural diet of a hexactinellid sponge: Benthic-pelagic coupling in a deep-sea microbial food web. Deep Sea Research Part I: Oceanographic Research Papers 53:1148-1156. DOI: 10.1016/j.dsr.2006.03.008.

Pita L., Rix L., Slaby BM., Franke A., Hentschel U. 2018. The sponge holobiont in a changing ocean: from microbes to ecosystems. Microbiome 6:46. DOI: 10.1186/s40168-018-0428-1.

Ploss M., Kuhn A. 2010. Kinetics of filamentous phage assembly. Physical Biology 7:45002. DOI: $10.1088 / 1478-3975 / 7 / 4 / 045002$.

Pollock F., Wood-Charlson E., van Oppen M., Bourne D., Willis B., Weynberg K. 2014. Abundance and morphology of virus-like particles associated with the coral Acropora hyacinthus differ between healthy and white syndrome-infected states. Marine Ecology Progress Series 510:39-43. DOI: 10.3354/meps 10927.

Proctor LM. 1997. Advances in the study of marine viruses. Microscopy Research and Technique 37:136-161. DOI: 10.1002/(SICI)1097-0029(19970415)37:2<136::AIDJEMT3>3.0.CO;2-M.

Rohwer F., Thurber RV. 2009. Viruses manipulate the marine environment. Nature 459:207212. DOI: $10.1038 /$ nature 08060 .

Rosario K., Breitbart M. 2011. Exploring the viral world through metagenomics. Current Opinion in Virology 1:289-297. DOI: 10.1016/j.coviro.2011.06.004.

Roux S., Enault F., Hurwitz BL., Sullivan MB. 2015. VirSorter: mining viral signal from microbial genomic data. PeerJ 3:e985. DOI: 10.7717/peerj.985.

Russel M. 1991. Filamentous phage assembly. Molecular microbiology 5:1607-13.

Schmitt S., Tsai P., Bell J., Fromont J., Ilan M., Lindquist N., Perez T., Rodrigo A., Schupp PJ., Vacelet J., Webster N., Hentschel U., Taylor MW. 2012. Assessing the complex sponge microbiota: core, variable and species-specific bacterial communities in marine sponges. The ISME Journal 6:564-576. DOI: 10.1038/ismej.2011.116.

Seymour J., Patten N., Bourne D., Mitchell J. 2005. Spatial dynamics of virus-like particles and heterotrophic bacteria within a shallow coral reef system. Marine Ecology Progress Series 288:1-8. DOI: 10.3354/meps288001.

Suttle CA. 2007. Marine viruses - major players in the global ecosystem. Nature Reviews Microbiology 5:801-812. DOI: 10.1038/nrmicro1750.

Thomas T., Moitinho-Silva L., Lurgi M., Björk JR., Easson C., Astudillo-García C., Olson JB., Erwin PM., López-Legentil S., Luter H., Chaves-Fonnegra A., Costa R., Schupp PJ., Steindler L., Erpenbeck D., Gilbert J., Knight R., Ackermann G., Victor Lopez J., Taylor MW., Thacker RW., Montoya JM., Hentschel U., Webster NS. 2016. Diversity, structure and convergent evolution of the global sponge microbiome. Nature Communications 7:11870. DOI: $10.1038 /$ ncomms11870.

Thomassen S., Riisgård H. 1995. Growth and energetics of the sponge Halichondria panicea. Marine Ecology Progress Series 128:239-246. DOI: 10.3354/meps128239. 
503

Thurber RLV., Correa AMS. 2011. Viruses of reef-building scleractinian corals. Journal of Experimental Marine Biology and Ecology 408:102-113. DOI: 10.1016/j.jembe.2011.07.030.

Thurber RV., Payet JP., Thurber AR., Correa AMS. 2017. Virus-host interactions and their roles in coral reef health and disease. Nature Reviews Microbiology 15:205-216. DOI: 10.1038/nrmicro.2016.176.

Vacelet J., Boury-Esnault N. 1995. Carnivorous sponges. Nature 373:333-335. DOI: $10.1038 / 373333 \mathrm{a} 0$.

Vacelet J., Gallissian M-F. 1978. Virus-like particles in cells of the sponge Verongia cavernicola (demospongiae, dictyoceratida) and accompanying tissues changes. Journal of Invertebrate Pathology 31:246-254. DOI: 10.1016/0022-2011(78)90014-9.

Van Soest RWM ., Boury-Esnault N., Vacelet J., Dohrmann M., Erpenbeck D., De Voogd NJ., Santodomingo N., Vanhoorne B., Kelly M., Hooper JNA. 2012. Global diversity of sponges (Porifera). PloS one 7:e35105. DOI: 10.1371/journal.pone.0035105.

Webster NS., Taylor MW. 2012. Marine sponges and their microbial symbionts: Love and other relationships. Environmental Microbiology 14:335-346. DOI: 10.1111/j.14622920.2011.02460.x.

Webster NS., Thomas T. 2016. The Sponge Hologenome. mBio 7:e00135-16. DOI: 10.1128/mBio.00135-16.

Weynberg KD., Laffy PW., Wood-Charlson EM., Turaev D., Rattei T., Webster NS., van Oppen MJH. 2017a. Coral-associated viral communities show high levels of diversity and host auxiliary functions. PeerJ 5:e4054. DOI: 10.7717/peerj.4054.

Weynberg KD., Neave M., Clode PL., Voolstra CR., Brownlee C., Laffy P., Webster NS., Levin RA., Wood-Charlson EM., van Oppen MJH. 2017b. Prevalent and persistent viral infection in cultures of the coral algal endosymbiont Symbiodinium. Coral Reefs 36:773-784. DOI: $10.1007 / \mathrm{s} 00338-017-1568-7$.

Weynberg KD., Wood-Charlson EM., Suttle CA., van Oppen MJH. 2014. Generating viral metagenomes from the coral holobiont. Frontiers in Microbiology 5:1-11. DOI: 10.3389/fmicb.2014.00206.

Wilson WH., Chapman DM. 2001. Observation of virus-like particles in thin sections of the plumose anemone, Metridium senile. Journal of the Marine Biological Association of the UK 81:879-880. DOI: 10.1017/S0025315401004726.

Wilson WH., Dale AL., Davy JE., Davy SK. 2005. An enemy within? Observations of virus-like particles in reef corals. Coral Reefs 24:145-148. DOI: 10.1007/s00338-004-0448-0.

Wood-Charlson EM., Weynberg KD., Suttle CA., Roux S., van Oppen MJH. 2015. Metagenomic characterization of viral communities in corals: mining biological signal from methodological noise. Environmental Microbiology 17:3440-3449. DOI: 10.1111/14622920.12803.

Wörheide G., Dohrmann M., Erpenbeck D., Larroux C., Maldonado M., Voigt O., Borchiellini 
542 C., Lavrov DV. 2012. Deep Phylogeny and Evolution of Sponges (Phylum Porifera).

543 Advances in Marine Biology 61:1-78. DOI: 10.1016/B978-0-12-387787-1.00007-6. 


\section{Figure 1}

Representative morphotypes of virus-like particles associated with GBR and Red Sea sponges.

GBR sponge species: (A, J, K, L) Carteriospongia foliascens, (B) Xestospongia sp., (C, F, G) Echinochalina isaaci, (E) Cinachyrella schulzei. Red Sea sponge species: (D, H) Stylissa carteri, (K) Amphimedon ochracea. TEM preparation method: (A, J, K) ultrathin sections of sponge tissue, (B-I, L) viral purification via filtration of sponge mucus. Scale bar: $200 \mathrm{~nm}$. Black arrows indicate the viral tail and white arrows indicate the VLPs.

*Note: Auto Gamma Correction was used for the image. This only affects the reviewing manuscript. See original source image if needed for review. 


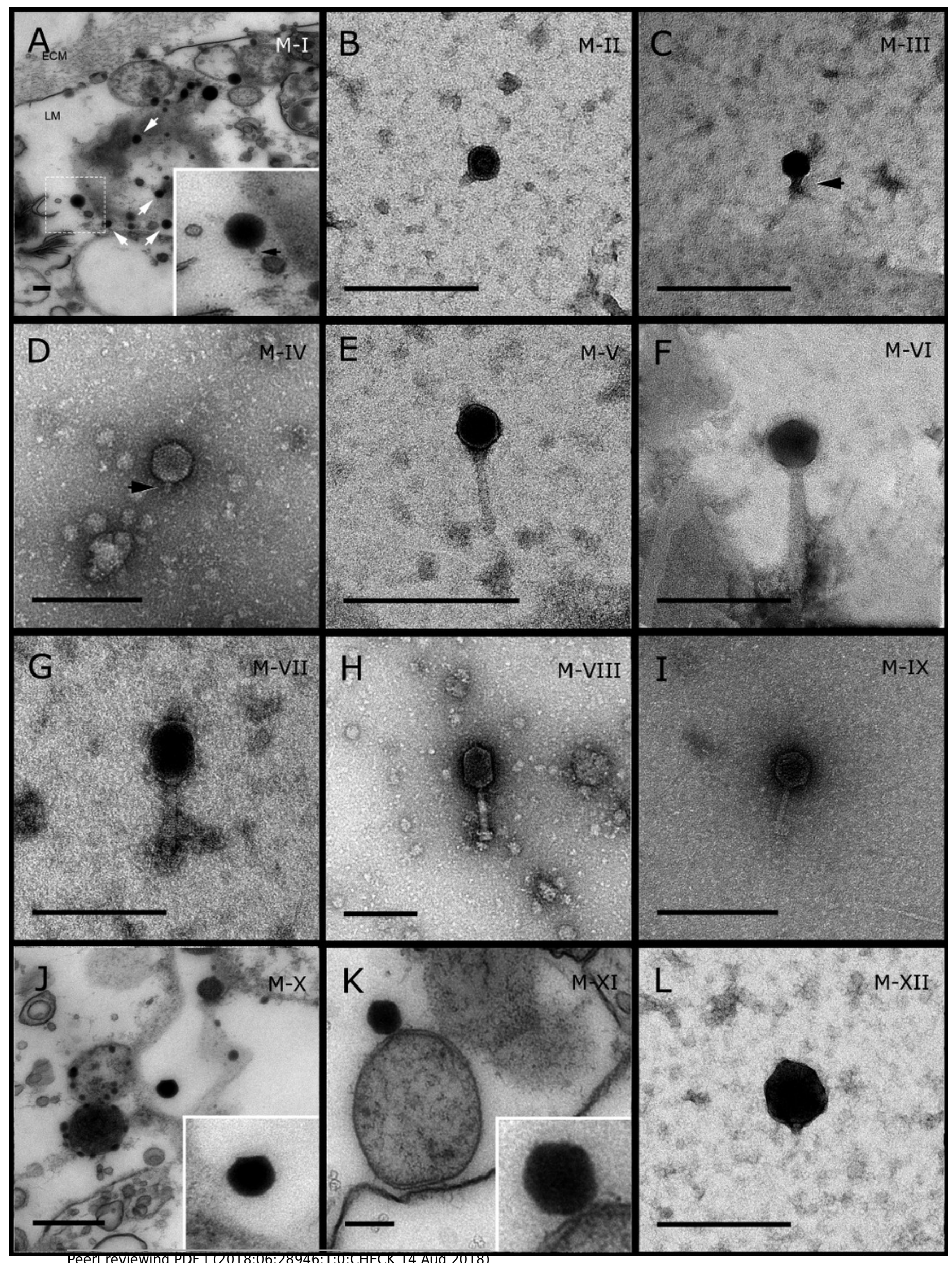


Figure 2

Representative morphotypes of virus-like particles associated with GBR sponges.

Sponge species: (A) Carteriospongia foliascens, (B, C) Stylissa carteri, (D) Xestospongia sp., (E-H) Pipestela candelabra, (I-K) Lamellodysidea herbacea, (L) Cinachyrella schulzei. TEM preparation method: $(A, H-K)$ viral purification via filtration of sponge mucus, $(B-F, L)$ viral purification via $\mathrm{CsCl}$ gradient centrifugation, $(\mathrm{G})$ ultrathin sections of sponge tissue. Scale bar: $200 \mathrm{~nm}$.

*Note: Auto Gamma Correction was used for the image. This only affects the reviewing manuscript. See original source image if needed for review. 


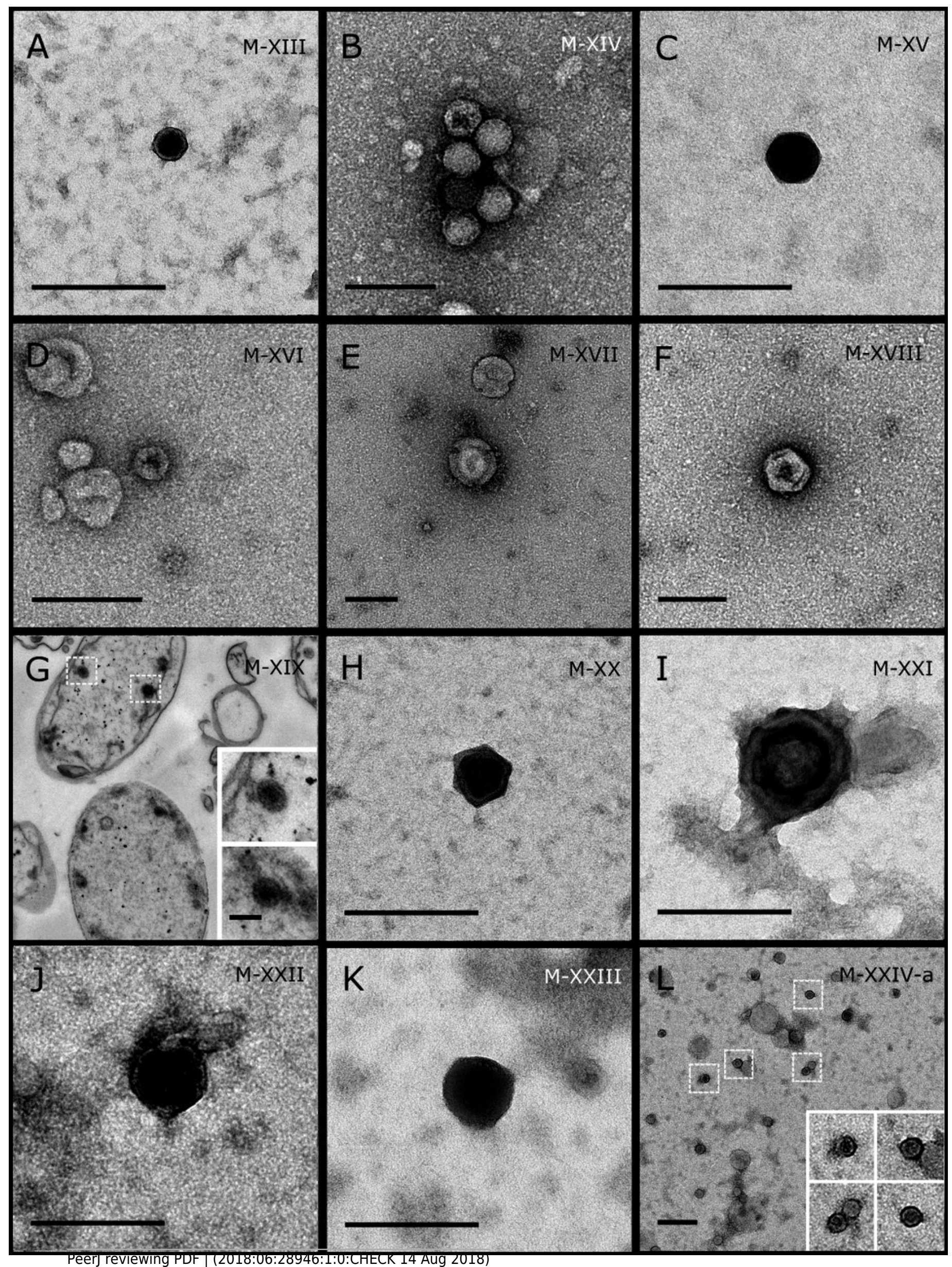




\section{Figure 3}

Representative morphotypes of virus-like particles associated with GBR and Red Sea sponges.

GBR sponge species: (A, B) Cinachyrella schulzei, (C) Cymbastella marshae. Red Sea sponge species: (D, E) Carteriospongia foliascens, (F-H) Stylissa carteri, (I) Xestospongia testudinaria, (J-L) Hyrtios erectus. TEM preparation method: (A, D-E, I-L) ultrathin sections of sponge tissue, (B, C, F-H) viral purification via filtration of sponge mucus. Scale bar: (A-C, E-L) 200 $\mathrm{nm}$, (D) $500 \mathrm{~nm}$. Black arrows indicate the VLPs.

*Note: Auto Gamma Correction was used for the image. This only affects the reviewing manuscript. See original source image if needed for review. 


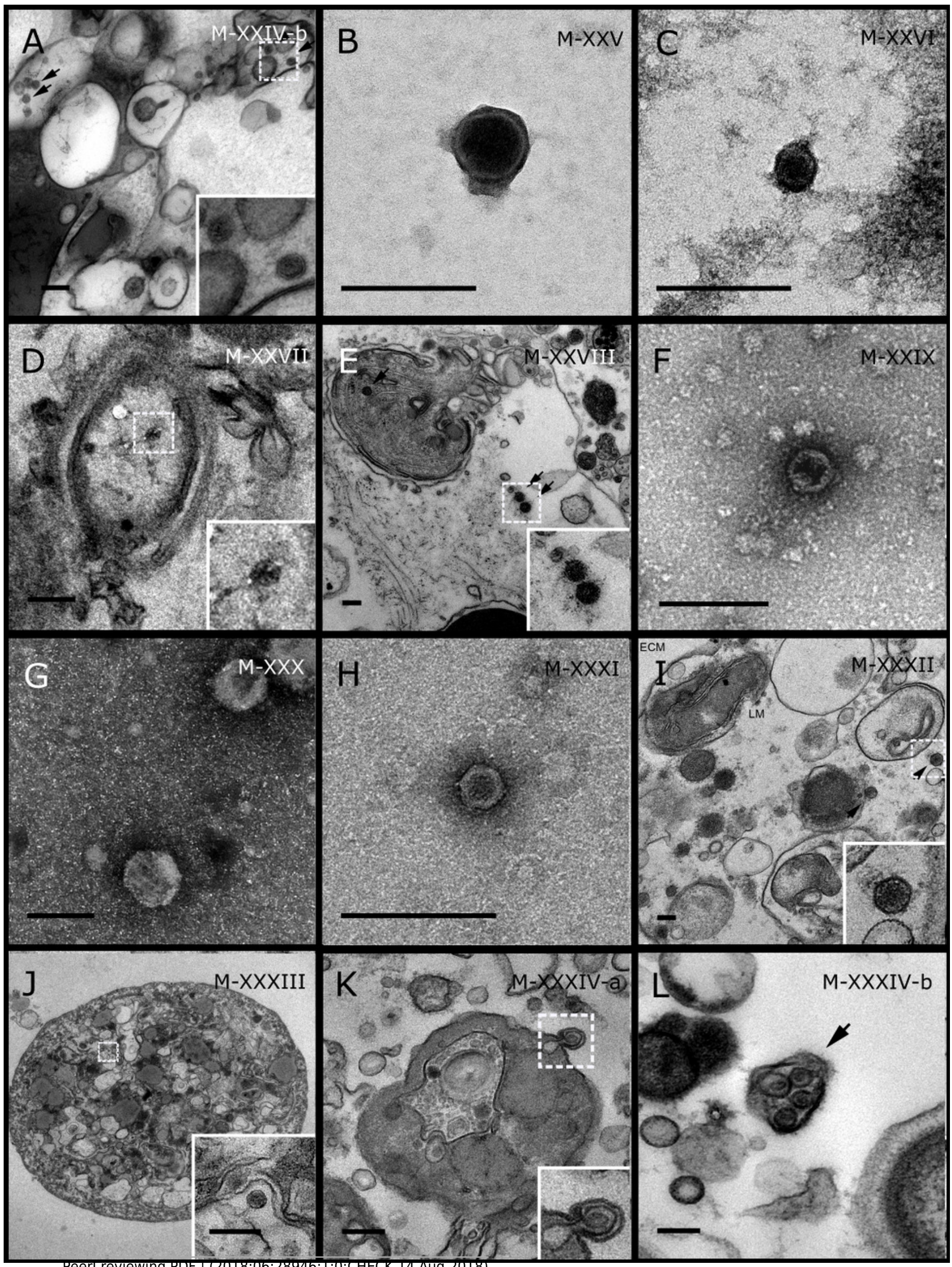




\section{Figure 4}

Representative morphotypes of virus-like particles associated with GBR and Red Sea sponges.

GBR sponge species: (A) Mycale sp., (B) Carteriospongia foliascens, (C, D) Xestospongia sp., (E) Cinachyrella schulzei. Red Sea sponge species: $(F, G)$ Carteriospongia foliascens, $(H, I)$ Stylissa carteri, (J-L) Xestospongia testudinaria. TEM preparation method: (A, B, D, E, H, I) viral purification via filtration of sponge mucus, (C) viral purification via $\mathrm{CsCl}$ gradient centrifugation, (F, G, J-L) ultrathin sections of sponge tissue. Scale bar: (A-E, H, I) $200 \mathrm{~nm}$, (F, G, J-L) $500 \mathrm{~nm}$.

*Note: Auto Gamma Correction was used for the image. This only affects the reviewing manuscript. See original source image if needed for review. 


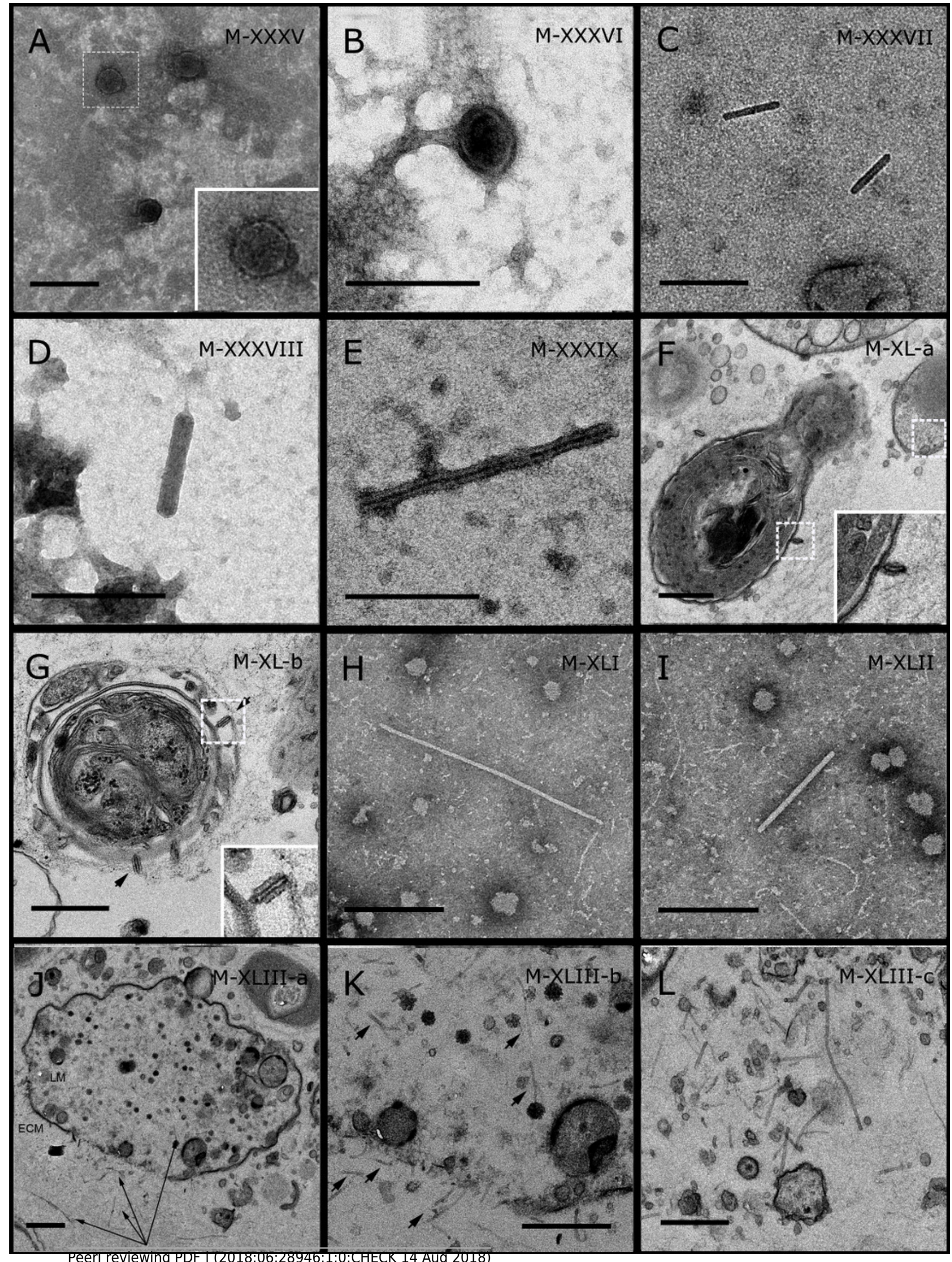




\section{Figure 5}

Representative morphotypes of virus-like particles associated with GBR and Red Sea sponges.

GBR sponge species: (C) Lamellodysidea herbacea, (I) Carteriospongia foliascens. Red Sea sponge species: (A, B, H) Crella cyathophora, (D-G) Amphimedon ochracea, (J-L) Hyrtios erectus. TEM preparation method: (A, $C, D)$ viral purification via filtration of sponge mucus, (B, E-L) ultrathin sections of sponge tissue. Scale bar: (D) $100 \mathrm{~nm},(\mathrm{~A}-\mathrm{C}, \mathrm{E}, \mathrm{H}-\mathrm{L}) 200 \mathrm{~nm},(\mathrm{~F}, \mathrm{G})$ $5 \mu \mathrm{m}$. ECM: External Cell Matrix, om: outer membrane, im: inner membrane, $\mathrm{cm}$ : core membrane, Ib: lateral bodies; c: core, e: external membrane; b: bacterium. Black arrows indicate the VLPS.

*Note: Auto Gamma Correction was used for the image. This only affects the reviewing manuscript. See original source image if needed for review. 


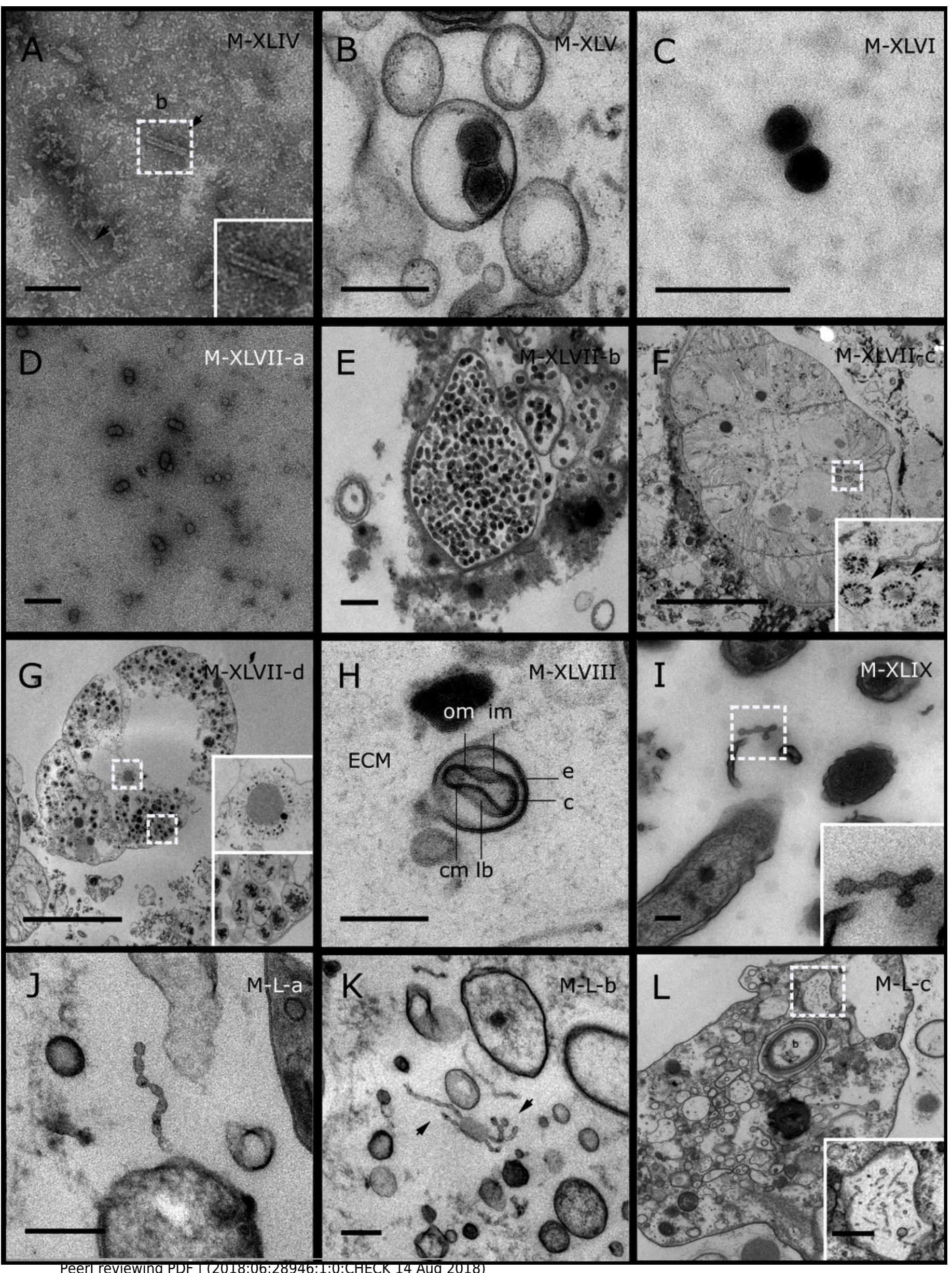




\section{Table $\mathbf{1}$ (on next page)}

Collection details for all sponge species examined by TEM.

GBR refers to the Great Barrier Reef collection site and RS refers to the Red Sea collection site. 


\begin{tabular}{lll} 
Sponge Species & Location & Depth (m) \\
\hline Carteriospongia foliascens, P.S. Pallas (1766) & GBR, RS & $3-10$ \\
Stylissa carteri, A. Dendi (1889) & GBR, RS & $10-15$ \\
Xestospongia sp. & GBR & $5-15$ \\
Lamellodysidea herbacea, C. Keller (1889) & GBR & $5-10$ \\
Cymbastela marshae, J.N.A.Hooper \& P.R. Bergquist (1992) & GBR & $10-15$ \\
Cinachyrella schulzei, C. Keller (1891) & GBR & $3-7$ \\
Pipestela candelabra, B. Alvarez et al. (2008) & GBR & $7-15$ \\
Echinochalina isaaci, J.N.A. Hooper (1996) & GBR & $7-15$ \\
Xestospongia testudinaria, J.B.P. Lamarck (1815) & RS & $7-15$ \\
Amphimedon ochracea, C. Keller (1889) & RS & $7-15$ \\
Hyrtios erectus, C. Keller (1889) & RS & $5-15$ \\
Crella (Grayela) cyathophora, H.J. Carter (1869) & RS & $7-15$ \\
Mycale sp. & RS & $5-15$
\end{tabular}

